\title{
Garbage Management Training for Women and Teacher in the Bureau of Logistics Office Medan North Sumatera
}

\author{
Rahmawaty $^{1 *}$ ), Abdul Rauf ${ }^{2}$ ), Widya Astuti ${ }^{3}$ ) \\ ${ }^{1}$ )Departmen of Forestry, Faculty of Forestry, Universitas Sumatera Utara, Medan, North \\ Sumatra, Indonesia \\ ${ }^{2}$ )Departmen of Land Science, Faculty of Agriculture, Universitas Sumatera Utara, Medan, \\ North Sumatra, Indonesia \\ $\left.{ }^{3}\right)$ Dharma Wanita at Bulog (Bureau of Logistics) \\ Email: rahmawaty@usu.ac.id
}

\begin{abstract}
The problem of garbage in Medan City is one of the problems that needs to be addressed immediately. The program of community service activities aims to provide training to the community on how to process garbage into something useful. This Community Service was conducted for women and teachers in Bureau of Logistics (Bulog) Foundation teachers with presentation, discussion and garbage management practices. Presentation activities carried out by the community service team by providing material on how to process household organic garbage into compost in the Bulog Office Hall, Medan. After finishing the presentation of the material, participants were given the opportunity to discuss about the material provided to the questions and answers or responses. After the presentation and discussion, follow the training on how to make compost from household organic garbage in Sei Semayang Village, Deli Serdang Regency. The positive responses were received with a good reception at the arrival of the community service team at the location and at the time the presentation and training were conducted. This activity was successfully carried out with the support of woman and Bulog foundation teachers.
\end{abstract}

Keyword: Compost, Garbage, Management, Training

\begin{abstract}
Abstrak
Masalah sampah di Kota Medan merupakan salah satu masalah yang perlu segera ditangani. Tujuan kegiatan ini adalah untuk memberikan pelatihan kepada masyarakat tentang cara mengolah sampah menjadi sesuatu yang berguna. Pelaksanaan Pengabdian ini dilakukan kepada Ibu-ibu Dharma Wanita dan guru Yayasan Bulog dengan metode ceramah, diskusi dan praktek pengelolaan sampah. Kegiatan ceramah dilakukan oleh tim pengabdian kepada masyarakat dengan memberikan materi tentang upaya pengolahan sampah organik rumah tangga menjadi kompos di Aula Kantor Bulog, Medan. Setelah selesai pemaparan materi, peserta diberikan kesempatan untuk diskusi tentang materi yang diberikan berupa tanya jawab atau tanggapan. Setelah kegiatan ceramah dan diskusi, dilanjutkan dengan pelatihan mengenai cara pembuatan kompos dari sampah organik rumah tangga di Desa Sei Semayang, Kabupaten Deli Serdang. Hasil yang diperoleh adalah adanya respon positif ditunjukkan dengan sambutan yang baik pada saat kedatangan tim pengabdian pada masyarakat ke lokasi dan pada saat ceramah dan pelatihan di lakukan. Kegiatan ini berhasil dilakukan dengan dukungan partisipasi ibu-ibu Dharma Wanita dan guru Yayasan Bulog.
\end{abstract}

Kata Kunci: Kompos, Sampah, Pengelolaan, Pelatihan

\section{PENDAhUluan}

Masalah sampah sangat memprihatinkan di Wilayah Provinsi Sumatera Utara, khususnya di kota Medan. Buang sampah di sembarang tempat telah menjadi perilaku buruk kebanyakan masyarakat. Kurangnya kesadaran akan kelestarian lingkungan juga masih kita dapatkan di lingkungan masyarakat kita. Salah satu diantaranya adalah masalah sampah. Padahal, sampah dapat dijadikan sebagai ajang kreatifitas dan menambah pendapatan, diantaranya adalah mengolah sampah tersebut menjadi sesuatu yang bermanfaat. Sampah Rumah Tangga terdiri dari sampah organik dan anorganik. Sampah organik dibagi dua, yaitu : sampah organik hijau (sisa sayur mayur dari dapur) seperti : tangkai/daun singkong, papaya, kangkung, bayam, kulit terong, wortel, labu siam, ubi, singkong, kulit buah-buahan, nanas, pisang, nangka, daun pisang, semangka, ampas kelapa, sisa sayur / lauk pauk, dan sampah dari kebun (rumput, daun-daun kering/basah) dan sampah organik 
hewan yang dimakan seperti: ikan, udang, ayam, daging. Sampah anorganik berupa bahan-bahan seperti: kertas, karton, kaleng, bermacam-macam jenis an plastik, dan styrofoam. Sampah organik hijau dipisahkan dari sampah organik hewan agar kedua bahan ini bisa diproses tersendiri untuk dijadikan kompos. Sedangkan sampah anorganik berupa plastik dikurangi pemakaiannya, memakai ulang barang-barang yang diperlukan, didaur ulang, yang masih bersih dikumpulkan dan diberikan kepada pemulung. Kompos sangat berguna dalam memanfaatkan sampah organik (berasal dari benda hidup) menjadi material yang dapat menyuburkan tanah (pupuk kompos). Selain itu, pembuatan kompos secara komersil dapat dijadikan sebuah peluang usaha. Pembuatan kompos dapat dijadikan jalan keluar dalam mengelola limbah. Seiring dengan berjalannya waktu, sampah yang dihasilkan manusia akan terus bertambah dengan meningkatnya kebutuhan hidup manusia tersebut. Sampah yang tidak dikelola dengan baik dapat menimbulkan pencemaran lingkungan, bahkan sampah telah menjadi masalah serius di perkotaan. Kompos dapat dibuat untuk meminimalisasi efek negatif yang ditimbulkan sampah dengan membuatnya menjadi lebih bermanfaat secara ekologis maupun finansial. Pemanfaatan sampah organik pada pembuatan kompos ini dapat dijadikan jalan keluar dalam mencegah timbulnya kembali tumpukan sampah seberat ribuan ton yang telah menyebabkan longsor dan korban jiwa. Jika saja sebelumnya sampah tersebut dapat diolah menjadi kompos, maka musibah longsor dan korban jiwa dapat dihindarkan. Salah satu kegiatan nyata yang dapat diaplikasikan adalah pengelolaan sampah rumah tangga menjadi produk yang berguna seperti kompos. Kegiatan pelatihan ini dimaksudkan untuk melatih ibu ibu dharma wanita persatuan Bulog Divre Sumatera Utara untuk mengolah sampah rumah tangga menjadi kompos. Adapun tujuan yang hendak dicapai dari kegiatan ini adalah untuk meningkatkan peran ibu-ibu dharma wanita dalam upaya membantu pengelolaan sampah di kota Medan. Sasaran kegiatan ini adalah masyarakat khususnya ibu-ibu dharma wanita persatuan Bulog Divre Sumatera Utara.

Masalah pengelolaan sampah organik rumah tangga ternyata menjadi masalah juga bagi ibuibu rumah tangga yang sehari-hari mengelola sampah yang dihasilkan dari rumah tangga. Ibu-ibu rumah tangga yang tergabung dalam komunitas Dharma Wanita Persatuan Bulog Divisi Regional Sumatera Utara yang ada di Medan, merasa perlu untuk diberi pelatihan untuk mengelola sampah rumah tangganya menjadi sesuatu yang bermanfaat, salah satunya dapat di buat kompos. Berbekal masalah inilah, maka tim pengabdian pada masyarakat dari Fakultas Pertanian USU bermitra dengan Dharma Wanita Persatuan Divre Sumatera Utara bermaksud melakukan kegiatan Pengabdian Pada Masyarakat untuk melatih masyarakat khususnya ibu-ibu dharma wanita persatuan Bulog Divre Sumatera Utara yang berlokasi di Bulog Divre Sumatera Utara Jalan Gatot Subsoto No. 180 medan tentang bagaimana mengelola sampah organik rumah tangga menjadi kompos. Kegiatan pelatihan ini dimaksudkan untuk melatih ibu ibu dharma wanita persatuan Bulog Divre Sumatera Utara untuk mengolah sampah rumah tangga menjadi kompos. Adapun tujuan dari kegiatan ini adalah untuk meningkatkan peran ibu-ibu dharma wanita dan guru dalam upaya membantu pengelolaan sampah di kota Medan. Manfaat pelaksanaan pengabdian pada masyarakat ini dapat mengelola sampah rumah tangga terutama sampah organik secara mandiri menjadi sesuatu yang berguna, yaitu kompos. Selain itu, pengetahuan yang diperoleh dapat di terapkan dalam kehidupan sehari-hari baik dilingkungan rumah tangga, kantor, maupun sekolah.

\section{METODE PELAKSANAAN}

Pelaksanaan kegiatan pengabdian ini dilakukan dengan cara pelatihan dan diskusi. Pelatihan dan diskusi dilakukan dengan memberikan materi dan praktek tentang cara pembuatan kompos dari sampah organik rumah tangga. Pelaksanaan kegiatan yang ditawarkan tim pengabdian pada masyarakat dari Fakultas Kehutana dan Fakultas Pertanian USU adalah pemberian materi cara mengolah sampah organik menjadi kompos yang di lakukan di Kantor Dharma Wanita Persatuan Divre Sumatera Utara Jalan Gatot Subroto No. 180 Medan dan praktek pembuatan kompos dilakukan di Desa Sei Semayang Km 13.5 jalan Raya Binjai, Kabupaten Deli Serdang. Pelaksanaan kegiatan pengabdian ini dilakukan selama satu bulan mulai dari survey dan penentuan lokasi, kunjungan untuk perijinan, dan kegiatan penyuluhan. 
Pelaksanaan Pengabdian pada Ibu-ibu Dharma Wanita dan guru yayasan Bulog akan dilakukan dengan cara sebagai berikut:

1. Ceramah

Kegiatan ceramah dilakukan oleh staf pengajar dengan memberikan materi tentang upaya dan cara pengolahan sampah organik rumah tangga menjadi kompos.

2. Diskusi

Setelah selesai pemaparan materi, diberikan kesempatan untuk diskusi tentang materi yang diberikan berupa tanya jawab atau tanggapan.

3. Praktek

Setelah kegiatan ceramah dan diskusi, diberikan pelatihan mengenai cara pembuatan kompos dari sampah organik rumah tangga.

Materi terkait Pengolahan Sampah Organik adalah sebagai berikut:

1. Pengertian sampah organik

Sampah organik merupakan sampah yang dapat membusuk seperti sisa makanan, sisa sayuran, sisa buah-buahan dan sampah halaman. Pengolahan sampah organik umumnya menggunakan model teknologi pengomposan. Pengomposan memanfaatkan aktivitas mikroorganisme berupa bakteri, jamur, juga insekta dan cacing.

2. Cara membuat kompos

Ada beberapa cara menbuat kompos yang dirangkum dari beberapa literautr (Djumarni, dkk, 2015; Hadisuwito, 2007; Indriani, 2014; Litauditomo, 2007; Murbandono, 2000; Murbondo, 2004; Karmini, 2001; Purwendro dan Nurhidayat, 2006; Yuwono, 2006) adalah:

- Penyiapan wadah pembuatan kompos. Sediakan ember, pot bekas, ataupun wadah lainnya, upayakan terbuat dari plastik untuk menghindari karat akibat air lindi kompos. Lubangi bagian dasar dan letakkan di wadah yang dapat menampung rembesan air dari dalamnya.

- Penyiapan bahan baku kompos. Bahan baku berupa sampah organik yang usianya tidak lebih dari dua hari dan kadar air maksimal 50\%. Untuk mempermudah proses pengomposan, sampah yang masih berbentuk memanjang terlebih dahulu dipotong-potong secara manual hingga mencapai ukuran kurang lebih $5 \mathrm{~cm}$.

- Membuat tumpukan. Sampah organik hasil proses pemilahan ditumpukkan di wadah pengomposan. Masukkan sampah organik ke dalam wadah. Taburi dengan sedikit tanah, serbuk gergaji, atau kapur secara berkala. Jika ada kotoran binatang, kotoran tersebut dapat ditambahkan untuk meningkatkan kualitas kompos. Setelah penuh, tutup wadah dengan tanah dan diamkan.

- Menyiram tumpukan tersebut dengan air secara merata. Proses penyiraman ini dilakukan agar bakteri dapat bekerja secara optimal. Proses ini dilakukan jika tumpukan sampah terlalu kering. Kadar air yang ideal dari tumpukan sampah selama proses pengomposan adalah antara $50-60 \%$ dengan nilai optimal sekitar $55 \%$.

- Pemantauan suhu, agar bakteri patogen dan bibit gulma mati maka suhu harus dipertahankan pada kisaran $60-70{ }^{\circ} \mathrm{C}$.

- Pemanenan kompos. Setelah dua bulan, kompos sudah matang dan siap dipanen.

- Pengemasan kompos. Kompos siap dikemas untuk dipasarkan. Sebelum pengemasan hendaknya kompos diayak terlebih dahulu untuk menghomogenkan ukuran partikelnya. Pengemasan dibuat menarik agar konsumen lebih tertarik. Perlu diperhatikan kebersihan dan kerapian kemasan.

\section{HASIL DAN PEMBAHASAN}

Pelaksanaan di lapangan dilakukan dengan cara ceramah, diskusi dan praktek, oleh tim pengabdian kepada masyarakat di Kantor bulog, Medan. Hal ini dilakukan karena sebagian besar ibu-ibu Dharma Wanita dan guru yayasan Bulog dekat dengan lokasi tersebut. Materi yang disampaikan adalah tentang cara mengolah sampah organik yang berasal dari sampah rumah tangga menjadi kompos. 
Materi yang disampaikan sangat bermanfaat bagi peserta karena permasalahan yang disampaikan dapat dilihat secara langsung, sehingga terjadi diskusi yang sifatnya dua arah.

Kegiatan pelatihan ini selain diikuti oleh ibu-ibu darma wanita persatuan bulog juga melibatkan guru-guru SD dan SMP dari yayasan Bulog regional Sumatera Utara yang diwakili oleh kepala sekolah SD dan SMP serta beberapa guru. Para peserta pelatihan ini menyambut baik kegiatan ini karena menjadi salah satu sarana dalam menambah wawasan anggota dharma wanita serta guruguru dari yayasan Bulog tentang cara mengolah sampah organik menjadi kompos yang dapat dipraktekkan langsung di rumah mereka atau pun di lingkungan kantor dan sekolah. Pada Gambar 1, terlihat tim Pengabdian kepada masyarakat sedang memberikan materi Penyuluhan kepada ibuibu Dharma Wanita dan guru yayasan Bulog.

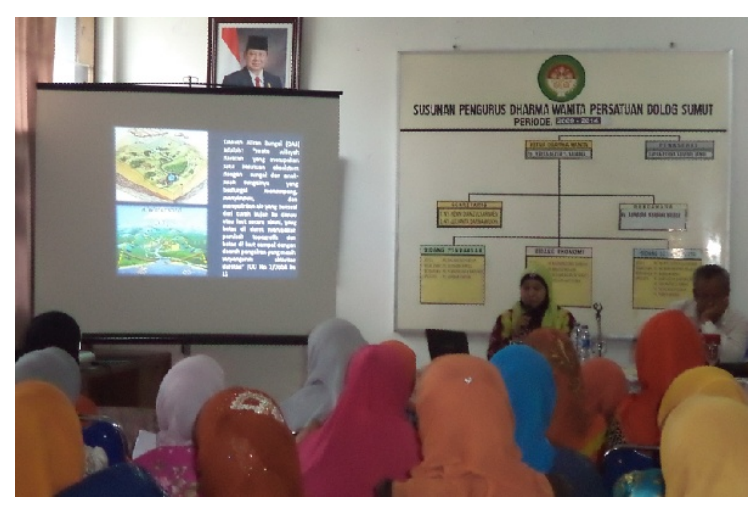

Gambar 3.1. Tim Pengabdian kepada masyarakat sedang memberikan materi Penyuluhan kepada ibu-ibu Dharma Wanita dan guru yayasan Bulog

Respon yang diberikan peserta pelatihan ini sangat positif. Hal ini terlihat pada Gambar 3.2 Sampai 3.4 , peserta dengan tekun mendengarkan ceramah dan aktif bertanya .

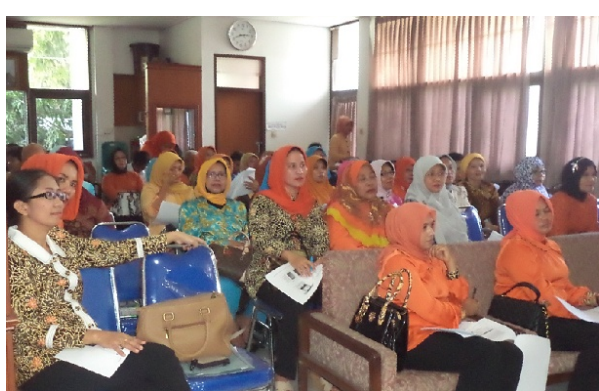

Gambar 3.2. Peserta pelatihan pemngolahan sampah organik rumah tangga menjadi kompos

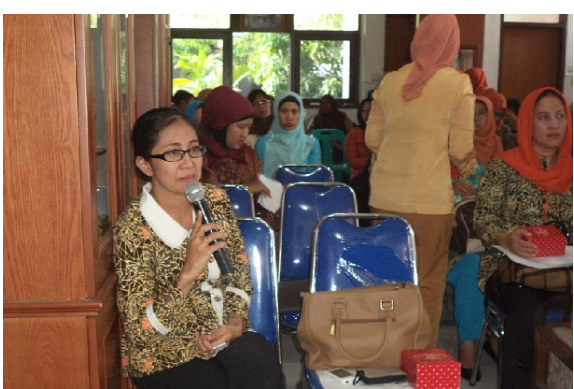

Gambar 3.3. Ketua Darma Wanita

Persatuan Bulog Divre Sumut memberikan pertanyaan kepada tim pengabdian dari USU 


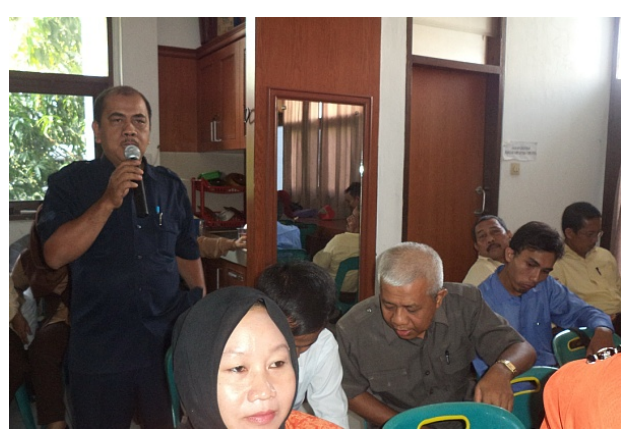

Gambar 3.4. Kepala Sekolah SMP Yayasan Bulog Divre Sumut memberikan pertanyaan kepada tim pengabdian dari USU

Pada kegiatan praktek pembuatan kompos di Desa Sei Semayang, terlihat bahwa ibu-ibu dan guru mencoba menggiling sampah organik rumah tangga. Mereka sangat senang diberikan pelatihan cara pembuatan kompos ini (Gambar 3.5 sampai Gambar 3.7).

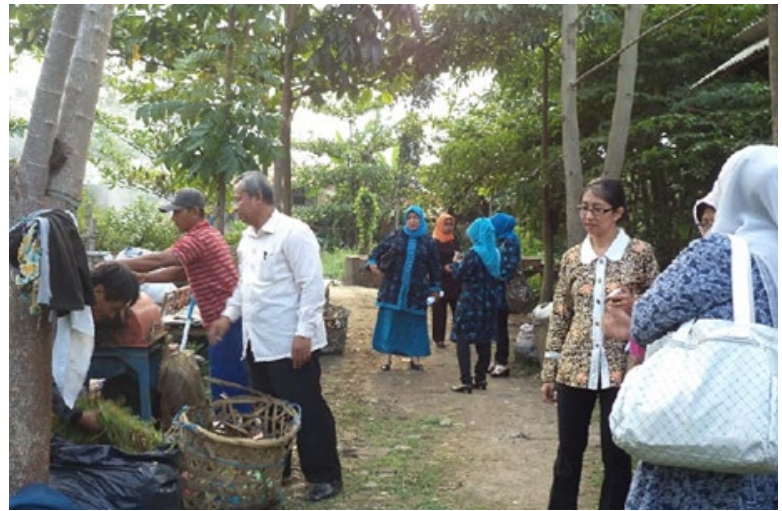

Gambar 3.5. Tim pengabdian dari USU sedang mempraktekkan cara pengolahan sampah organik menjadi kompos di sei semayang

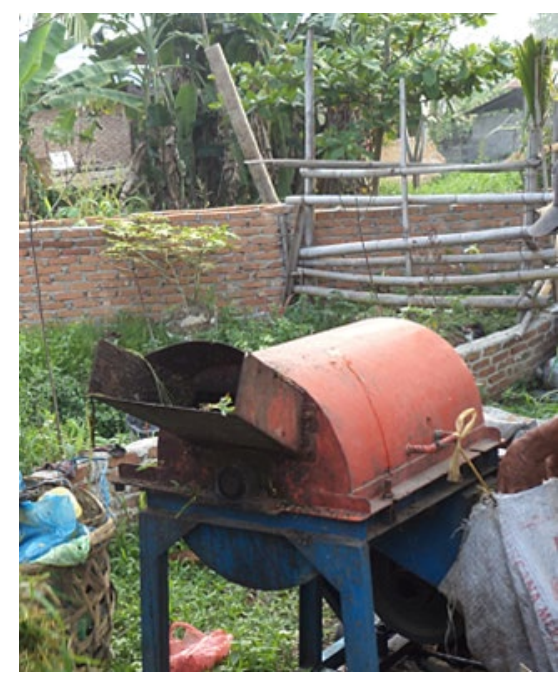

Gambar 3.6. Alat Penggiling sampah organik rumah tangga 


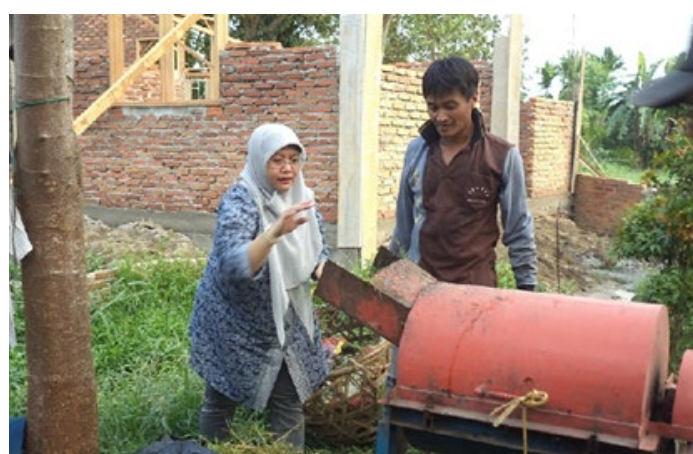

Gambar 3.7. Salah satu ibu Dharma Wanita Persatuan Bulog Divre Sumut mencoba menggiling sampah organik rumah tangga

Pada Gambar 3.8, terlihat hasil penggilingan sampah ornaik dimasukkan kedalam bak pembuatan kompos. Selanjutnya dalam beberapa hari, sampah organik tersebut sudah menjadi kompos yang siap untuk digunakan.

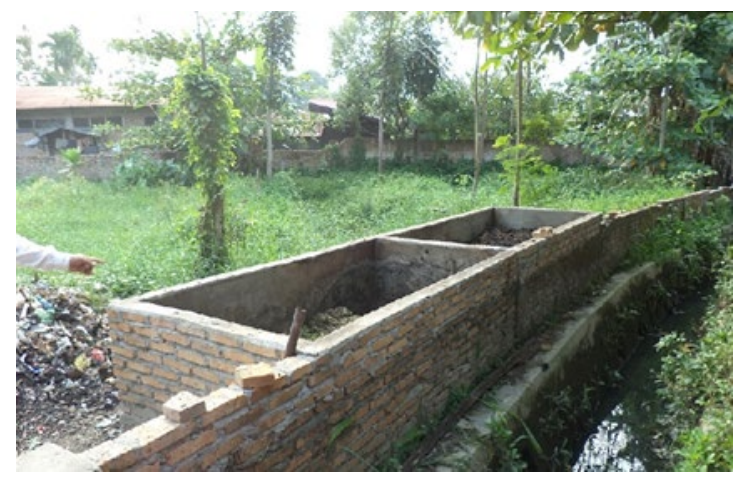

Gambar 3.8. Bak pembuatan kompos di Desa Sei Semayang

Beberapa peneliti telah melakukan cara untuk mendapatkan pupuk organik cair dengan bahan baku yang berbeda-beda (Riansyah dan Wesen (2010); Sarjono dkk (2013); Sinaga (2009)).

Pengolahan sampah organik dilakukan dengan cara mencacah sampah dengan alat pencacah, lalu diberi cairan yang mengandung mikroba (EM-4) (Simanungkalit et al. 2009), ditunggu selama dua minggu sambil setiap hari sampah diaduk-aduk hingga rata. Sampah yang baru dicacah diletakkan di rumah kompos dengan cara diletakkan di atas anyaman bambu, bagian bawah anyaman bambu diberi paving (agar ada ruang sehingga air hasil pengomposan mengalir ke saluran limbah cair). Sampah yang telah dicacah kemudian diberi cairan starter (EM-4) yang mengandung mikrobia melalui alat penyiram gembor hingga basah. Selain berfungsi dalam proses fermentasi dan dekomposisi bahan organik, EM4 juga mempunyai manfaat lain seperti: 1. Membasmi dan mencegah jamur secara biologis, 2.Memperbaiki sifat fisik, kimia dan biologi tanah , 3.Meningkatkan ketersediaan nutrisi tanah , 4.Menekan aktivitas hama dan penyakit pada tanaman (Sutrisari, 2013; Fitriani, 2008; Jalaludin dkk, 2016). Pembuatan pupuk cair dari limbah buahbuahan sebagai pupuk alternatif pengganti pupuk kimia sangat cocok dikembangkan. Selain bahan bakunya melimpah juga sangat ekonomis karena tidak memerlukan banyak biay.

Faktor pendukung dalam pelaksanaan pengabdian yang sangat membantu terealisasinya kegiatan ini yaitu adanya respon yang positif dari peserta ( $i b u-i b u$ Dharma wanita dan guru-guru yayasan Bulog). Respon positif ditunjukkan dengan sambutan yang baik pada saat kedatangan tim pengabdian pada masyarakat ke lokasi dan pada saat ceramah dan pelatihan di lakukan. Adapun faktor penghambat dalam kegiatan pengabdian ini, yaitu : keterbatasan tempat dan tidak semua ibuibu Dharma Wanita dan guru yayasan Bulog dapat ikut dalam kegiatan penyuluhan ini, oleh karena mereka telah mempunyai kegiatan lain yang bertepatan dengan acara ini. Namun demikian, kegiatan 
ini berhasil dilakukan dengan partisipasi sebagian besar ibu-ibu Dharma Wanita dan guru yayasan Bulog.

\section{KESIMPULAN}

\subsection{Kesimpulan}

Kegiatan pengabdian kepada masyarakat ini yang dilakukan dengan pelatihan dapat membuka wawasan ibu-ibu dan guru-guru mengenai cara mengelola sampah menjadi sesuatu yang bermanfaat seperti kompos. Kompos yang dihasilkan dapat menjadi pendapatan tambahan bagi ibu-ibu dan guru.

\subsection{Saran}

Saran yang dapat diberikan dalam kegiatan ini adalah diperlukan penyuluhan yang berkesinambungan kepada ibu-ibu Dharma Wanita dan guru yayasan Bulog agar lebih memahami pengolahan sampah organik rumah tangga menjadi kompos dan perlu dipilih waktu yang tepat yang disesuaikan dengan waktu keberadaan ibu-ibu Dharma Wanita dan guru yayasan Bulog sehingga dapat dilakukan penyuluh kepada ibu-ibu Dharma Wanita dan guru yayasan Bulog dalam jumlah yang lebih banyak..

\section{UCAPAN TERIMAKASIH)}

Ucapan terima kasih kepada Lembaga Pengabdian pada Masyarakat, Universitas Sumatera Utara dan Bulog Divisi Regional Sumatera atas fasilitas yang diberikan sehingga kegiatan pengabdian kepada masyarakat ini dapat berjalan dengan lancar. Terima kasih juga kami sampaikan kepada ibuibu Dharma Wanita Bulog dan guru-guru pada yayasan Bulog atas kerjasama yang baik dalam kegiatan pengabdian pada masyarakat ini.

\section{DAFTAR PUSTAKA (REFERENCES)}

Djuarmani, N., Kristian, B.S., Setiawan, 2005. Cara Tepat Membuat Kompos. Agromedia Pustaka, Jakarta.

Fitriani, Y. 2008. Pembuatan Pupuk Organik Cair dari Limbah Cair Industri Perikanan Menggunakan Asam Asetat dan EM4 (Effective Microorganisme 4). Skripsi. Bogor: Institut Pertanian Bogor.

Hadisuwito, S., (2007). Membuat Pupuk Kompos Cair. PT. Agromedia Pustaka, Jakarta

Indriani, Y.H., (2004). Membuat Kompos Secara Kilat. Penebur Swadaya, Jakarta

Jalaluddin, Nasrul ZA, R. Syafrina. (2016). Pengolahan Sampah Organik Buah- Buahan Menjadi Pupuk Dengan Menggunakan Effektive Mikroorganisme. Jurnal Teknologi Kimia Unimal 5(1): 17-29 
Karmini, M., Lya M.S., Murdiyati, Sofyan, S.A. (2001). Petunjuk Teknis Tata Cara Pengelolaan Sampah dengan Sistem Daur Ulang Pada Lingkungan. Bandung: Departemen Permukiman dan Prasarana Wilayah.

Murbandono, L.H.S., (2000). Membuat Kompos. Penebar Swadaya. Jakarta.

Murbondo, L. ( 2004). Pupuk Organik Padat, Pembuatan Aplikasi. Penebar Swadaya, Jakarta.

Purwendro. S., dan Nurhidayat. ( 2006). Mengolah Sampah untuk Pupuk dan Pestisida Organik. Seri Agritekno. Penebar Swadaya, Jakarta.

Riansyah Erwin dan Wesen Putu. (2010). Pemanfaatan Lindi Sampah sebagai Pupuk Cair. Jurnal Ilmiah Teknik Lingkungan Vol. 4 No. 1. Universitas Pembangunan Nasional "Veteran" Jawa Timur.

Sarjono, S.E., Surya, E., dan Herlina, N. (2013). Pembuatan Pupuk Cair dan Biogas dari campuran Limbah Sayuran. Jurnal Teknik Kimia Universitas Sumatera Utara. Medan.

Sinaga, D. ( 2009). Pembuatan Pupuk Cair dari Sampah Organik dengan menggunakan Boisca sebagai Starter. Skripsi. Medan: Universitas Sumatera Utara.

Simanungkalit, RDM., Suriadikarta, DA., Saraswati, R., Setyorini, D dan Hartatik W. (2009). Teknik Pembuatan Kompos. Balai Besar Litbang Sumberdaya Lahan Pertanian.

Sutrisari. S. (2013). EffectiveMikroorganisme 4(EM4).

Yuwono, D. (2006). Kompos dengan Cara Aerob maaupun Anaerob untuk Menghasilkan Kompos yang Berkualitas. Penebar Swadaya. Jakarta. 